\title{
Analysis of through-thickness heterogeneities of microstructure and texture in nickel after accumulative roll bonding
}

Zhang, Yubin; Mishin, Oleg; Godfrey, A.

Published in:

Journal of Materials Science

Link to article, DOI:

10.1007/s10853-013-7703-0

Publication date:

2014

Link back to DTU Orbit

Citation (APA):

Zhang, Y., Mishin, O., \& Godfrey, A. (2014). Analysis of through-thickness heterogeneities of microstructure and texture in nickel after accumulative roll bonding. Journal of Materials Science, 49, 287-293.

https://doi.org/10.1007/s10853-013-7703-0

\section{General rights}

Copyright and moral rights for the publications made accessible in the public portal are retained by the authors and/or other copyright owners and it is a condition of accessing publications that users recognise and abide by the legal requirements associated with these rights.

- Users may download and print one copy of any publication from the public portal for the purpose of private study or research.

- You may not further distribute the material or use it for any profit-making activity or commercial gain

- You may freely distribute the URL identifying the publication in the public portal

If you believe that this document breaches copyright please contact us providing details, and we will remove access to the work immediately and investigate your claim. 


\title{
Analysis of through-thickness heterogeneities of microstructure and texture in nickel after accumulative roll bonding
}

\author{
Y.B. Zhang ${ }^{1 *}$, O.V. Mishin ${ }^{1}$, A. Godfrey ${ }^{2}$ \\ ${ }^{1}$ Danish-Chinese Center for Nanometals, Section for Material Science and Advanced Characterization, \\ Department of Wind Energy, Technical University of Denmark, Risø Campus, 4000 Roskilde, Denmark \\ ${ }^{2}$ Key Laboratory of Advanced Materials, School of Material Science and Engineering, Tsinghua \\ University, Beijing 100084, P.R. China
}

\begin{abstract}
The through-thickness heterogeneity of the microstructure and texture have been investigated in pure nickel processed by 6 cycles of accumulative roll bonding with lubrication applied during each rolling pass. Strong rolling textures are found in the intermediate and center layers of the deformed sample, whereas increased fractions of the shear texture are observed near the surface. Significant differences at different depths are also revealed in the fractions of areas containing either predominantly low angle misorientations or predominantly high angle misorientations. It is found that the fractions of such areas are much more sensitive to the deformation history than the average parameters based on the measurements of the boundary spacing and fractions of high angle boundaries (HABs). For the material studied in the present work, the area fraction of the low misorientation regions appears to correlate with the summed fraction of the rolling texture components. The observed microstructural and textural variations are discussed and compared with literature data, taking into account the influence of large draught rolling and lubrication on the distribution of strain imposed during the accumulative roll bonding process.
\end{abstract}

Keywords: nickel; accumulative roll bonding (ARB); severe plastic deformation (SPD); deformed microstructure; texture

\footnotetext{
* Corresponding author. e-mail: yubz@dtu.dk; Tel.: 0045 46775876; Fax.: 004546775758.
} 


\section{Introduction}

Accumulative roll bonding (ARB) has become a widely used processing technique for producing submicrometer-crystalline or nanostructured materials by severe plastic deformation (SPD). During ARB large strains can be achieved by repetitive cycles of rolling (typically $50 \%$ reduction) followed by cutting of the rolled material in half and then stacking the halves for further rolling in a subsequent cycle $[1,2]$.

Similar to the observations of heavily deformed materials produced by other deformation techniques [3-6], it has been found that the average boundary spacing in ARB-processed materials decreases with increasing strain, whereas the fraction of high angle boundaries (HABs) increases [7-10]. The situation is however less clear when microstructural and textural homogeneity is considered. Whereas there is a general agreement [11-14] that carrying out ARB without lubrication does result in a significant through-thickness heterogeneity of texture, remarkable texture homogeneity has been claimed for Ni after 6-8 ARB cycles with lubrication [15]. Despite the large-draught rolling utilized during ARB (which is expected to produce pronounced shear texture components near the surface [16]), rolling-type textures were reported even for the immediate surface of this ARB-processed Ni sample, and very little difference was seen in the fractions of the rolling texture components between the surface and other locations [15]. The heterogeneity of the microstructure in ARB-processed Ni was also evaluated by considering such average parameters as the fraction of HABs and the HAB spacing [17], with the latter parameter analyzed at only two depths, which is hardly sufficient to support conclusions regarding the through-thickness homogeneity. Moreover, it has recently been shown [18] that the HAB fraction and the average boundary spacing do not always provide a good description of the extent of heterogeneity within a heavily deformed microstructure. In contrast, it has been demonstrated that partitioning of a deformed microstructure into subsets that contain either predominantly low angle misorientations or predominantly high angle misorientations can be used to provide a better quantitative characterization of microstructural heterogeneities in heavily deformed metals [18-21]. This approach is applied in the present work, where the microstructure and texture are examined over a large number of locations across the thickness of a nickel sample after 6 ARB cycles. The results obtained in our study are compared with literature data for both ARB-processed $\mathrm{Ni}$ and other heavily deformed materials. 


\section{Experiment}

A $2 \mathrm{~mm}$ thick strip of pure (99.967\%) nickel with a fully recrystallized microstructure and a nearly random texture was used as an initial material [10]. The average grain size (including annealing twins) in this sample was measured to be $\sim 20 \mu \mathrm{m}$. The strip was cold-rolled $50 \%$ using a 2-high rolling mill with a roll diameter of $310 \mathrm{~mm}$. The $1 \mathrm{~mm}$ thick sample obtained after this rolling was then cut in half. After degreasing and wire-brushing, the halves were stacked and rolled 50\% again, applying conditions of large-draught rolling [22,23] and creating a bonding between the two sheets. This rollbonding operation was conducted repeatedly to reach 6 ARB cycles, which corresponds to a total von Mises strain of $\varepsilon_{\mathrm{vM}}=4.8$. For each $\mathrm{ARB}$ cycle, rolling was conducted unidirectionally, followed by cooling in water immediately after deformation. A mineral oil was used as a lubricant.

The microstructure of the deformed sample was investigated using electron backscatter diffraction (EBSD) in a Zeiss Supra 35 field emission gun scanning electron microscope. EBSD maps were collected at 16 evenly distributed depths between the center and the surface in the section containing the normal and rolling directions (ND and RD, respectively). For each depth an area covering at least $30 \mu \mathrm{m}$ along the ND and $20 \mu \mathrm{m}$ along the RD was sampled with an EBSD map step size of $50 \mathrm{~nm}$. A critical misorientation angle $\left(\theta_{c}\right)$ of $2^{\circ}$ was used for defining the boundary spacing and fractions of different boundary types in the EBSD maps. In addition, TEM images were obtained from thin foils taken from near the center.

Texture components were defined within a $15^{\circ}$ deviation from the corresponding ideal orientations. The rolling texture components are represented in this work by the Brass “Bs” $\{110\}<112>$,

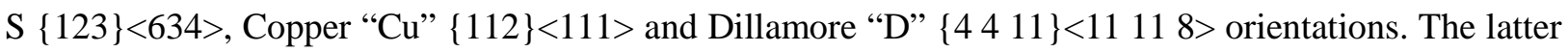
component is considered in this work along with the standard orientations of the rolling texture because it has been previously shown to be an important texture component in ARB-processed materials $[12,14,24,25]$. Shear texture components are represented by the $\{100\}<011>,\{111\}<011>,\{111\}<112>$ and $\{112\}<110>$ components [26]. The depth location of each investigated region is described by the ratio $t / t_{0}$, where $t$ is the distance from the mid-thickness of the sample and $t_{0}$ is the sample thickness. Thus, $\mathrm{t} / \mathrm{t}_{0}$ varies from a value of 0 at the center to a value of 0.5 at the surface. 


\section{Results}

A TEM image illustrating the microstructure near the center of the ARB sample is shown in Fig.1, where extended boundaries are seen to be closely aligned with the rolling plane. These boundaries form lamellar structures, characteristic of heavy rolling $[27,28]$. In addition to the observation of the lamellar structures, evidence of localized shear at $25-40^{\circ}$ to the $\mathrm{RD}$ is also revealed in this material (see Fig. 2). The average boundary spacing $d$ measured along the ND in TEM micrographs is $124 \mathrm{~nm}$, which is somewhat smaller than the values, approximately 150-160 nm, obtained from EBSD maps collected also near the center.

Although the EBSD technique misses a certain amount of boundaries with very low misorientations [29,30], it nevertheless provides very useful statistical information on through-thickness variations of texture, as well as on local heterogeneities of the microstructure. Figure 2 shows EBSD maps obtained from three different depths of the ARB sample and the corresponding pole figures. It is seen that both the center and quarter-thickness regions contain strong rolling textures (Fig. 2a,b). These rolling textures are however not identical. Whereas a combination of the $\mathrm{Cu}$ and $\mathrm{D}$ components dominate the texture near the center (see Fig. 2a), the crystallographic texture near the quarter thickness is dominated by the S component (see Fig. 2b). In contrast to these textures, the maximum intensity in the pole figure from the subsurface is located between the ideal shear $\{100\}<011>$ and nearest $\mathrm{D}$ orientation (Fig. 2c). As evident from the EBSD map in Fig. 2c, orientations of the shear texture components occupy a significant area in the subsurface. In this map, the group of orientations classified as "other" is dominated by orientations deviated by $15-25^{\circ}$ from the ideal shear texture components. To allow a quantitative analysis of the observed texture gradients, summed fractions of either the shear or rolling texture components are plotted in Fig. 3 as a function of $t / t_{0}$. It is seen that the shear texture components represent almost $30 \%$ of the material volume near the surface, becoming weaker with increasing distance from the surface. The fraction of the rolling texture first increases with distance from the surface, reaching $\sim 90 \%$ at $\mathrm{t} / \mathrm{t}_{0}=0.1-0.25$ and then decreases slightly near the center (see Fig. 3).

In contrast to the pronounced through-thickness texture heterogeneity, the boundary spacing data measured by EBSD along the ND reveals no systematic variation, as is evident from Fig.4a, which 
presents both the spacing between boundaries with misorientation angles $>2^{\circ}(d)$, and the $\mathrm{HAB}$ spacing $\left(d_{\mathrm{HAB}}\right)$. The average values for these spacings, taking data over all depths covered by the EBSD investigation, are $\sim 160 \mathrm{~nm}$ and $\sim 300 \mathrm{~nm}$ for $d$ and $d_{\mathrm{HAB}}$, respectively. Similarly, no strong variation with depth is seen for the fraction of $\mathrm{HABs}, f_{\mathrm{HAB}}$, where the average value is approximately $50 \%$ (see Fig. $4 \mathrm{~b}$ ).

To obtain a clearer description of the microstructural heterogeneity produced by the ARB process, EBSD maps have been partitioned into high and low misorientation subsets (HMS and LMS, respectively). This approach has been previously applied for characterizing heterogeneity in microstructural refinement in samples deformed to large strains by either equal channel angular extrusion (ECAE) or compression [18-21]. The partitioning is based on the idea of detecting continuous areas within an EBSD map that have not been subdivided by boundaries of large misorientation angles, and such areas represent a heterogeneity in the effective refinement of the deformed microstructure. In practice the method uses the grain reconstruction algorithms within the commercially available EBSD post-processing systems and requires setting values for the low angle misorientation threshold and for the critical area size. Based on previous studies, low misorientation regions are defined in the present experiment as areas greater than $2.5 \mu \mathrm{m}^{2}$ surrounded by boundaries $>5^{\circ}$, and collectively these regions form the low misorientation subset (LMS). The remaining areas in the deformed microstructure represent the HMS. Examples of the partitioned maps are shown in Fig. 5. It is apparent that the HMS fraction, $f_{\text {HMS }}$, is lower in the EBSD map from the quarter-thickness as compared to the two other maps. The through-thickness variation of $f_{\mathrm{HMS}}$ is further quantified in Fig. 6 , where it is seen that the $f_{\mathrm{HMS}}$ values are large near the surface and the center. The lowest value of $f_{\mathrm{HMS}}$ is found at $\mathrm{t} / \mathrm{t}_{0}=0.15$ (see Fig. 6).

\section{Discussion}

\subsection{Variation of microstructural parameters}

The analysis of the boundary spacing and the fraction of HABs in our ARB-processed Ni sample does not reveal systematic through-thickness variations, which is in agreement with previous reports on other materials heavily deformed by ARB [13,31]. Values of $d$ and $f_{\mathrm{HAB}}$ obtained from EBSD maps should however be analyzed with some circumspection because these values are affected by the limited angular resolution of the EBSD technique [29], due to which misorientations less than $1.5-2^{\circ}$ are 
typically not taken into account. This results in an overestimation of both the fraction of HABs and the boundary spacing, as evident in our experiment from the substantially greater value of $d$ measured by EBSD as compared to the TEM-determined value. Thus, the boundary spacing data and the proportions of different boundary types extracted from EBSD data in materials with a substantial frequency of very low misorientations should be considered only as a rough estimate of true values. Furthermore, the present observations show that a lack of great variation in either $d$ or $f_{\mathrm{HAB}}$ does not necessarily imply homogeneity of a deformed material, and that significant through-thickness variations become apparent when the microstructure is partitioned into HMS and LMS (see Fig. 6). Unlike the boundary spacing (d) and fraction of high angle boundaries $\left(f_{\mathrm{HAB}}\right)$ parameters, the HMS/LMS fractions are not biased by the limited angular resolution of EBSD and can thus be conveniently used to characterize the heterogeneity of microstructural refinement in samples deformed to large strains.

The higher HMS fractions observed both in the subsurface and near the center of the ARBprocessed sample correlate well with expected increase in the amount of shear deformation in the subsurface layers due to large-draught rolling $[16,22,23]$. Note that the center layer in our ARB sample was the surface layer in the fifth ARB cycle, and thus also experienced a significant shear strain before being subjected to conditions approaching plane strain compression (PSC) in the sixth cycle. This additional shear strain in the subsurface and center layers results in increased frequencies of boundary misorientations greater than $5^{\circ}\left(f_{\left[\theta>5^{\circ}\right]}\right)$ as shown in Table 1 (note that this was the value chosen in our work as the critical angle for partitioning into LMS and HMS components).

In addition, Table 1 also gives the total length of boundary traces per unit area for misorientations $>5^{\circ}, L_{A\left[\theta>5^{\circ}\right]}$, estimated directly from the number, $N_{\left[\theta>5^{\circ}\right]}$, of adjacent pixel misorientations in this range [32]. For a heavily rolled microstructure, where misorientations greater than $5^{\circ}$ are produced mostly across lamellar boundaries being almost parallel to either $\mathrm{X}$ or $\mathrm{Y}$ axis of the EBSD map, $L_{A\left[\theta>5^{\circ}\right]} \approx N_{\left[\theta>5^{\circ}\right]} \Delta / A$, where $\Delta$ is the map step size and $A$ is the map area [32] (the approximation arises due to the discrete nature of the underlying EBSD data grid). It is important to emphasize that in contrast to $f_{\left[\theta>5^{\circ}\right]}$, which depends on the choice of the critical boundary misorientation angle $\theta_{\mathrm{c}}, L_{A\left[\theta>5^{\circ}\right]}$ does not depend on the choice of $\theta_{c}$ and so is not affected by the limited angular resolution of the EBSD data. Considering the higher average values of both $f_{\left[\theta>5^{\circ}\right]}$ and $L_{A\left[\theta>5^{\circ}\right]}$ in the subsurface and center regions, it is 
not surprising that the HMS fractions are also higher in these regions, as compared to that at $\mathrm{t} / \mathrm{t}_{0}=0.1-0.25$. Thus, it is apparent that the fractions of HMS/LMS are much more sensitive to the deformation history than the average parameters based on the measurements of the boundary spacing and fractions of HABs. A similar conclusion has been drawn by Mishin and Bowen [18] following an analysis of through-thickness variations in ECAE-processed copper.

\subsection{Texture gradients}

Even though rolling in the present experiment was conducted with lubrication, significant through-thickness texture gradients are revealed in the ARB-processed Ni sample (Fig. 2 and Fig. 3). This result is in contrast to the conclusions drawn by Bhattacharjee et al. [15] regarding the homogeneity of the rolling texture in $\mathrm{Ni}$ deformed using similar rolling conditions. One possible reason for the differences in the observed extent of texture variation data could be that in the work presented in [15] the EBSD data for the surface, where the heterogeneity is expected to be most pronounced, were collected in the rolling plane with only a few deformed grains contributing to the texture statistics in the EBSD map. The presence of strong through-thickness variations of texture in our sample is however in agreement with ARB simulation data of $\mathrm{Li}$ et al. [14] and with predictions of texture heterogeneities resulting from large draught rolling [16].

Whereas previous ARB experiments conducted on dry rolls demonstrated a strong $\{001\}<110>$ texture component near the sample surface [11-14], the maximum intensity in the subsurface texture in our work was observed in positions deviating by $\sim 10^{\circ}$ from the exact location of the $\{001\}<110>$ component (see Fig. 2c) that is considered to be the major component of the shear texture $[22,23,26]$. It is therefore apparent that the lubrication used in the present experiment reduced the shear strain component so that the accumulated shear was not high enough to produce a strong $\{001\}<110>$ component in the subsurface of our sample, though it was sufficiently high to rotate orientations in a large sample volume close to this component.

For the center layer of an ARB-processed sheet, orientations of the shear texture are expected to rotate towards components of the rolling texture, producing high intensities of the $\mathrm{D} / \mathrm{Cu}$ components [14], as also observed near the center of our sample (see Fig. 2a). Although no significant fraction of the shear texture is preserved in the center after the last rolling pass, the rolling texture here is not as strong 
as at $\mathrm{t} / \mathrm{t}_{0}=0.1-0.25$ (see Fig. 3 and Table 1 ), where the material volume has been deformed under conditions similar to PSC over a large number of passes. It can therefore be suggested that the center regions of the ARB-processed material still exhibit some inherited influence of shear deformation from the preceding pass when this layer was in direct contact with rolls.

In general, the summed fraction of the rolling texture appears to correlate with the area fraction of the LMS, as shown in Fig. 7, where the greatest LMS fraction is observed for $t / t_{0}=0.1-0.25$, which also show the highest fraction of the rolling texture. A possible explanation of this correlation is that both $f_{\mathrm{LMS}}$ and $f_{\text {Rol }}$ are strongly affected by the increased shear in the two last ARB cycles.

The observed variations in both texture and the heterogeneity in microstructural refinement highlight the fact that even though the average boundary spacing approaches a saturation value with increasing number of ARB cycles [10], the microstructure and texture experience significant changes as each successive surface layer is moved to the center and then deformed under PSC conditions.

\section{Conclusions}

Through-thickness gradients of the microstructure and texture have been investigated by EBSD mapping of pure nickel processed by 6 ARB cycles, where each rolling pass was conducted at room temperature with lubrication. The following conclusions are reached in this study.

1. A well-refined microstructure with an average boundary spacing of $\sim 160 \mathrm{~nm}$, as measured from EBSD maps, is formed in the sample. The fraction of high angle boundaries after 6 cycles is approximately 50\%. No systematic through-thickness variations are identified for either of these two parameters.

2. In contrast to the boundary spacing and the fraction of HABs, analysis of HMS/LMS area fractions reveals significant through-thickness variations. Increased HMS fractions are observed in the subsurface and near the center, which is attributed to the fact that these volumes experienced increased shear deformation in at least one of the two last ARB cycles.

3. The distribution of different texture components is also non-uniform throughout the thickness. Strong rolling textures are found in the intermediate and center layers. Near the surface, where the rolling texture is very weak, components of the shear texture in total occupy $30 \%$ of all orientations. The 
summed fraction of the rolling texture appears to correlate with the LMS area fraction.

\section{Acknowledgements}

The authors gratefully acknowledge the support from the Danish National Research Foundation (Grant No. DNRF86-5) and the National Natural Science Foundation of China (Grant No. 51261130091) to the Danish-Chinese Center for Nanometals. ZYB also acknowledges Professor Tsuji and Dr. Sun for their help with the ARB-processing.

\section{References}

[1] Saito Y, Tsuji N, Utsunomiya H, Sakai T, Hong RG (1998) Scr Mater 39:1221-1227

[2] Saito Y, Utsunomiya H, Tsuji N, Sakai T (1999) Acta Mater 47:579-583

[3] Liu Q, Huang X, Lloyd DJ, Hansen N (2002) Acta Mater 50:3789-3802

[4] Mishin OV, Juul Jensen D, Hansen N (2003) Mater Sci Eng A 342:320-328

[5] Zhang HW, Huang X, Hansen N (2008) Acta Mater 56:5451-5465

[6] Mishin OV, Juul Jensen D, Hansen N (2010) Metall Mater Trans A 41:2936-2948

[7] Lee SH, Saito Y, Sakai T, Utsunomiya H (2002) Mater Sci Eng A 325:228-235

[8] Terada D, Inoue S, Tsuji N (2007) J Mater Sci 42:1673-1681

[9] Eizadjou M, Manesh HD, Janghorban K (2009) J Alloys Compd 474:406-415

[10] Zhang YB, Mishin OV, Kamikawa N, Godfrey A, Liu W, Liu Q (2013) Mater Sci Eng A 576:160166

[11] Heason CP, Prangnell PB (2002) Mater Sci Forum 396-402:429-434

[12] Kim HW, Kang SB, Tsuji N, Minamino Y (2005) Metall Mater Trans A 36:3151-3162

[13] Kamikawa N, Tsuji N, Huang X, Hansen N (2007) Mater Trans 48:1978-1985 
[14] Li S, Sun F, Li H (2010) Acta Mater 58:1317-1331

[15] Bhattacharjee PP, Terada D, Tsuji N (2009) In: Haldar A, Suwas S; Bhattacharjee D (eds.), Microstructure and texture in steels, 421-429, Springer

[16] Schoenfeld SE, Asaro RJ (1996) Int J Mech Sci 38:661-683

[17] Bhattacharjee PP, Tsuji N, Ray RK (2011) Metall Mater Trans A 42:2769-2780

[18] Mishin OV, Bowen JR (2009) Metall Mater Trans A 40:1684-1692

[19] Godfrey A, Mishin OV, Yu TB (2012) Mater Sci Forum 715-716:203-210

[20] Mishin OV, Segal VM, Ferrasse S (2012) Metall Mater Trans A 40:4767-4776

[21] Luo ZP, Mishin OV, Zhang YB, Zhang HW, Lu K (2012) Scr Mater 66:335-338

[22] Truszkowski W, Krol J, Major B. (1980) Metall. Trans. A 11:749-758

[23] Truszkowski W, Krol J, Major B. (1982) Metall. Trans. A 13:665-669

[24] Pirgazi H, Akbarzadeh A, Petrov R, Sidor J, Kestens L (2008) Mater Sci Eng A 492:110-117

[25] Roy S, Nataraj BR, Suwas S, Kumar S, Chattopadhyay K (2012) J Mater Sci 47:6402-6419

[26] Engler O, Huh M-Y, Tomé CN (2000) Metall Mater Trans A 31:2299-1692

[27] Hughes DA, Hansen N (1993) Metall Trans A 24:2021-2037

[28] Hughes DA, Hansen N (2000) Acta Mater 48:2985-3004

[29] Humphreys FJ (2001) J Mater Sci 36:3833-3854

[30] Mishin OV, Godfrey A, Östensson L (2006) Metall Mater Trans A 37:489-496

[31] Li BL, Tsuji N, Kamikawa N (2006) Mater Sci Eng A 423:331-342

[32] Godfrey A, Cao WQ, Hansen N, Liu Q (2005) Metall Mater Trans A 36:2371-2378 


\section{Figure captions}

Fig. 1. TEM micrograph showing the microstructure near the center of the ARB sample.

Fig. 2. EBSD maps and $\{111\}$ pole figures from three different depths of the ARB sample: (a) near the center $\left(\mathrm{t} / \mathrm{t}_{0} \approx 0\right)$; (b) quarter-thickness $\left(\mathrm{t} / \mathrm{t}_{0} \approx 0.25\right)$; (c) subsurface $\left(\mathrm{t} / \mathrm{t}_{0} \approx 0.5\right)$. In $(\mathrm{a}-\mathrm{c})$ areas having orientations within $15^{\circ}$ of either shear or rolling texture components are shown in red and blue, respectively. In (b) incomplete bonding is observed near coarse oxide particles, seen as black features in the map. White lines in the EBSD maps correspond to misorientations $\theta=2-15^{\circ}$ and black lines show high angle $\left(>15^{\circ}\right)$ boundaries. The scale bar is parallel to the $\mathrm{RD}$. In the pole figures, the contour lines are at $1,2,3,5$ and $8 \times$ random.

Fig. 3. Summed fractions of either rolling or shear texture components at different depths. Letters "C" and "S" correspond to the center and surface, respectively.

Fig. 4. Variation of microstructural parameters as a function of $t / t_{0}$ : (a) boundary spacing along the ND for all boundaries observed in the EBSD maps, $d$, and for HABs, $d_{\mathrm{HAB}}$; (b) fraction of HABs. Letters "C" and "S" correspond to the center and surface, respectively.

Fig. 5. HMS and LMS in the EBSD maps shown in Fig. 3: (a) near the center $\left(t / t_{0} \approx 0\right)$; (b) quarterthickness $\left(\mathrm{t} / \mathrm{t}_{0} \approx 0.25\right) ;$ (c) subsurface $\left(\mathrm{t} / \mathrm{t}_{0} \approx 0.5\right)$. White lines in the EBSD maps correspond to misorientations $\theta=2-15^{\circ}$ and black lines show high angle $\left(>15^{\circ}\right)$ boundaries. The scale bar is parallel to the RD.

Fig. 6. HMS and LMS area fractions as a function of sample depth. Letters "C" and "S" correspond to the center and surface, respectively.

Fig. 7. Correlation between the fraction of the rolling texture and the LMS fraction, $f_{\text {Rol }}$ and $f_{\text {LMS }}$, respectively. 
Figure 1

Click here to download high resolution image

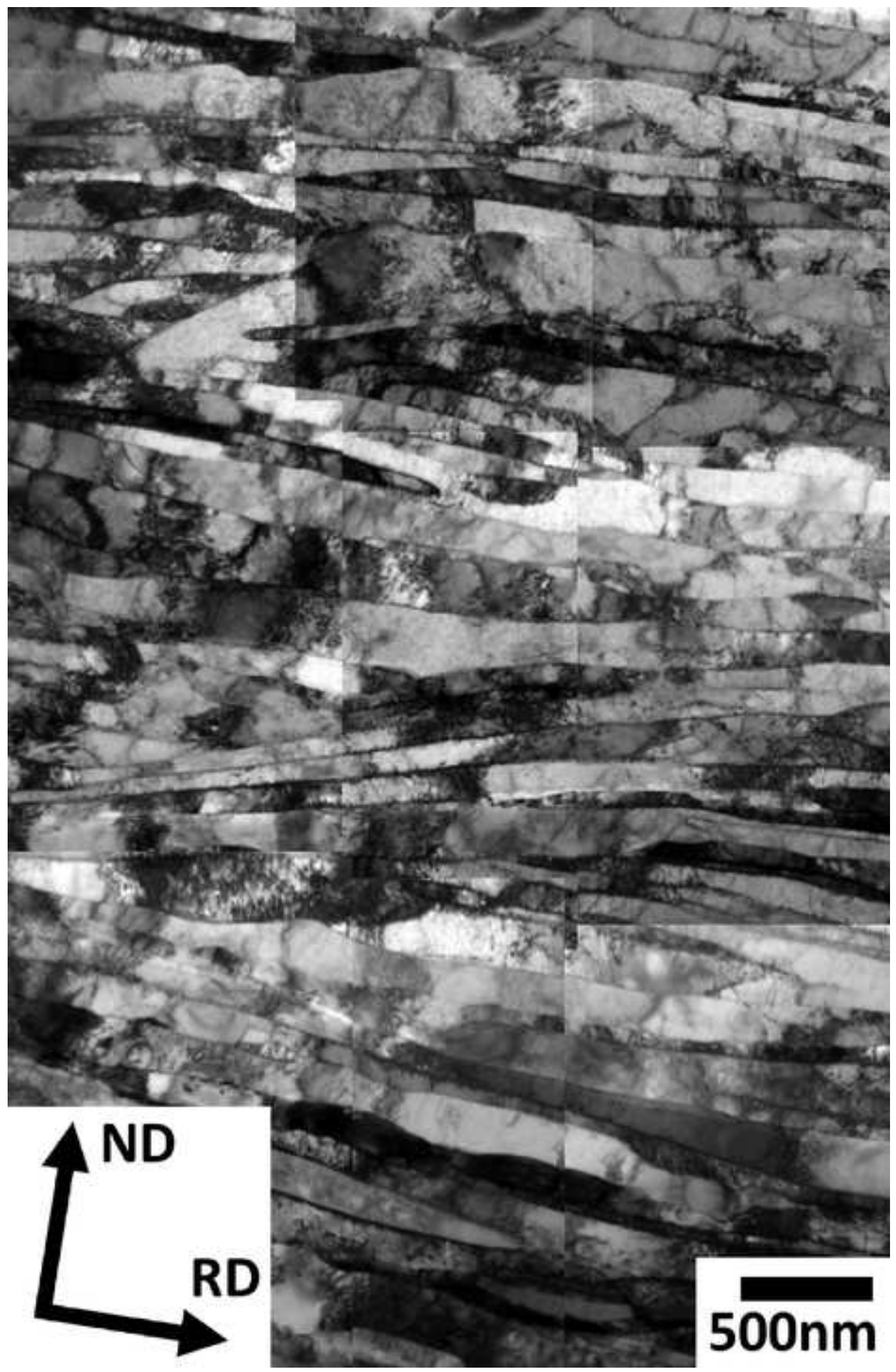




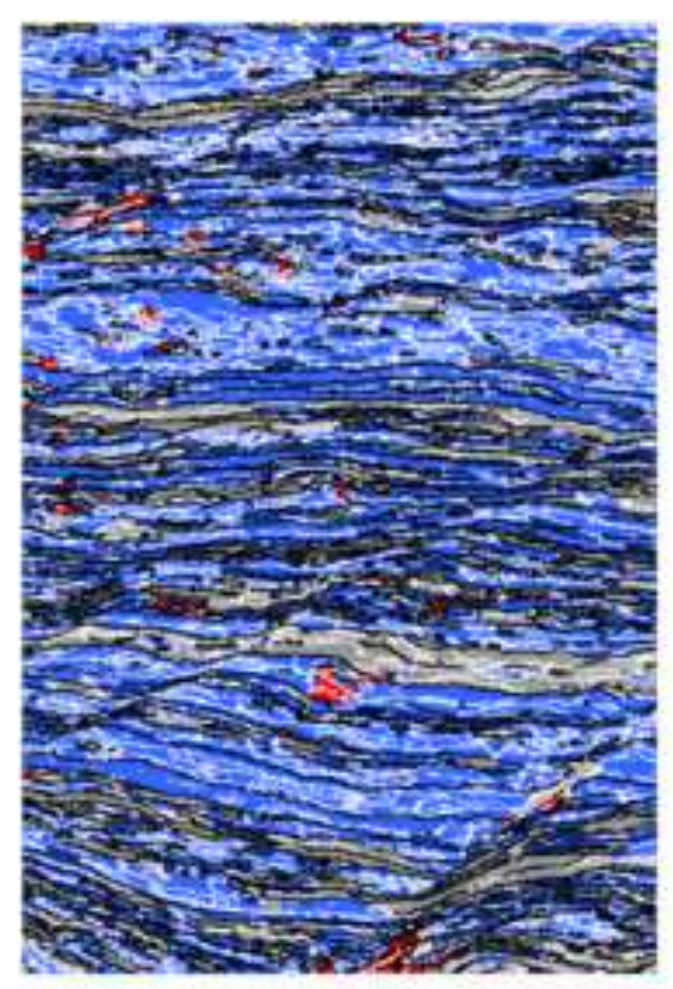

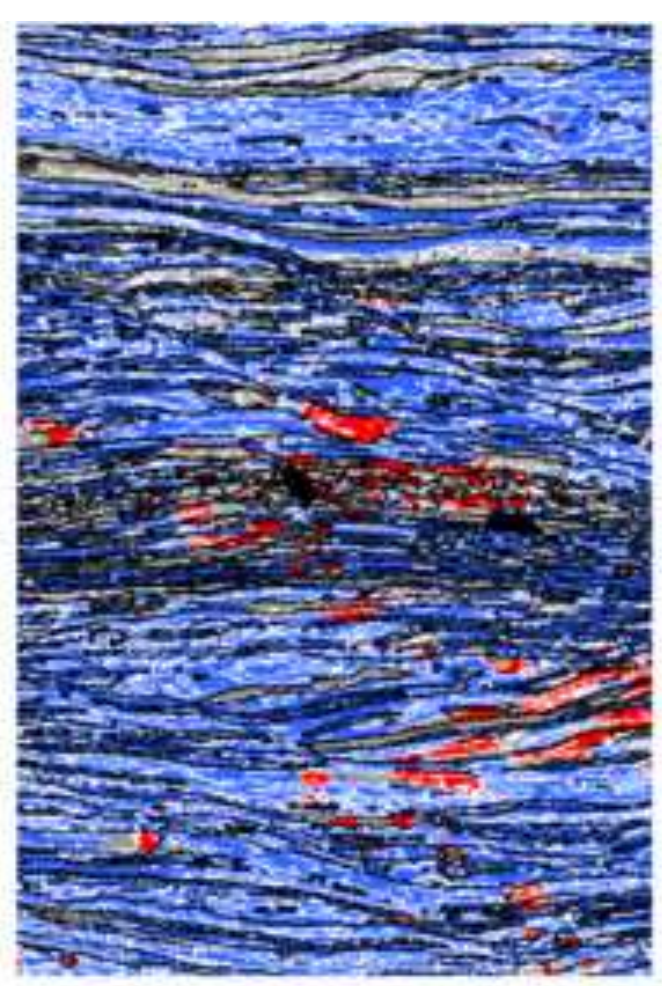

Shear
Other

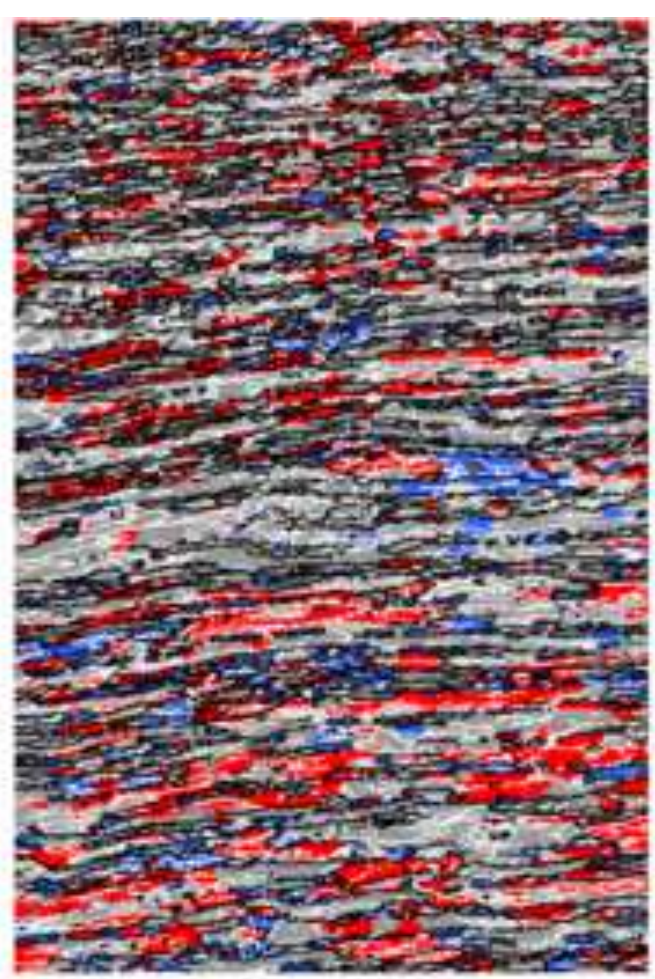

$5 \mu \mathrm{m}$

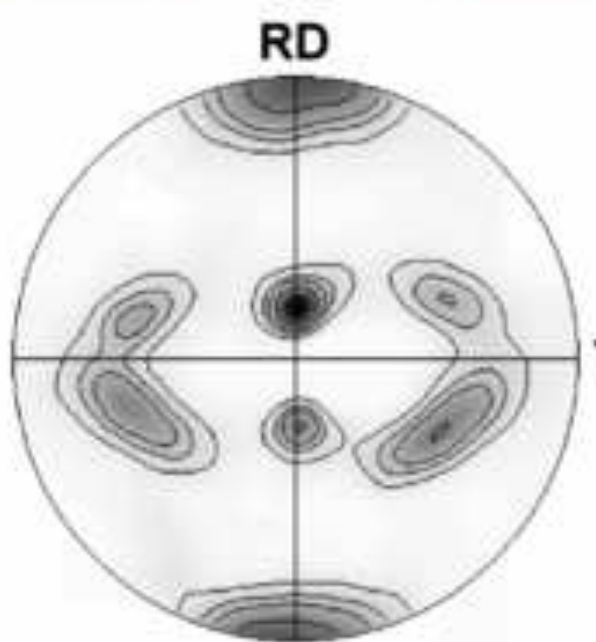

(a)

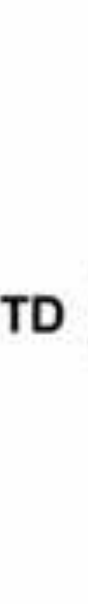

D

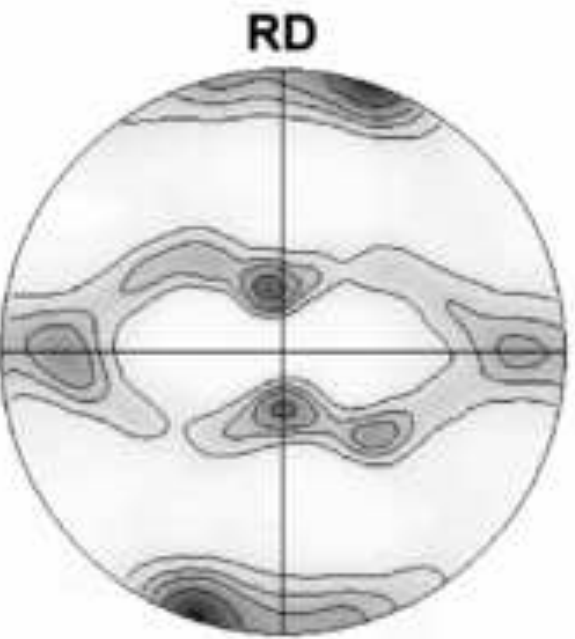

(b)
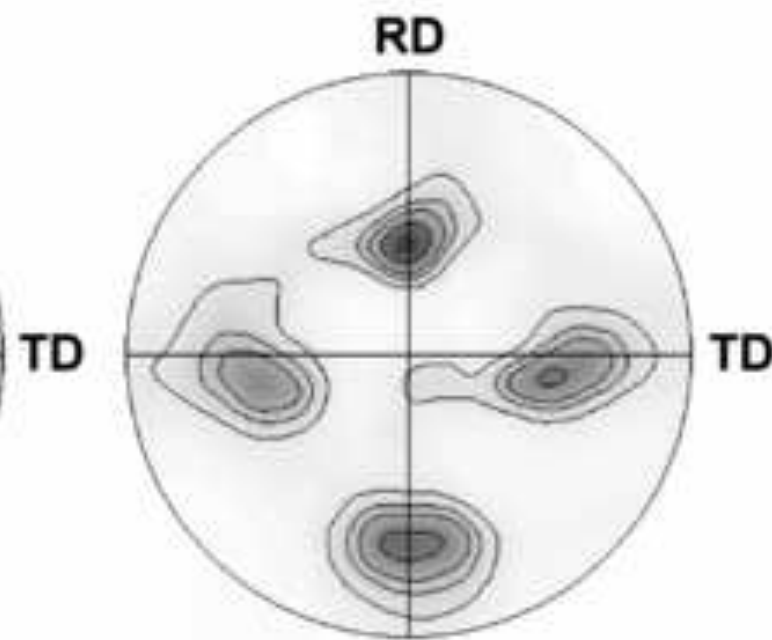

(c) 


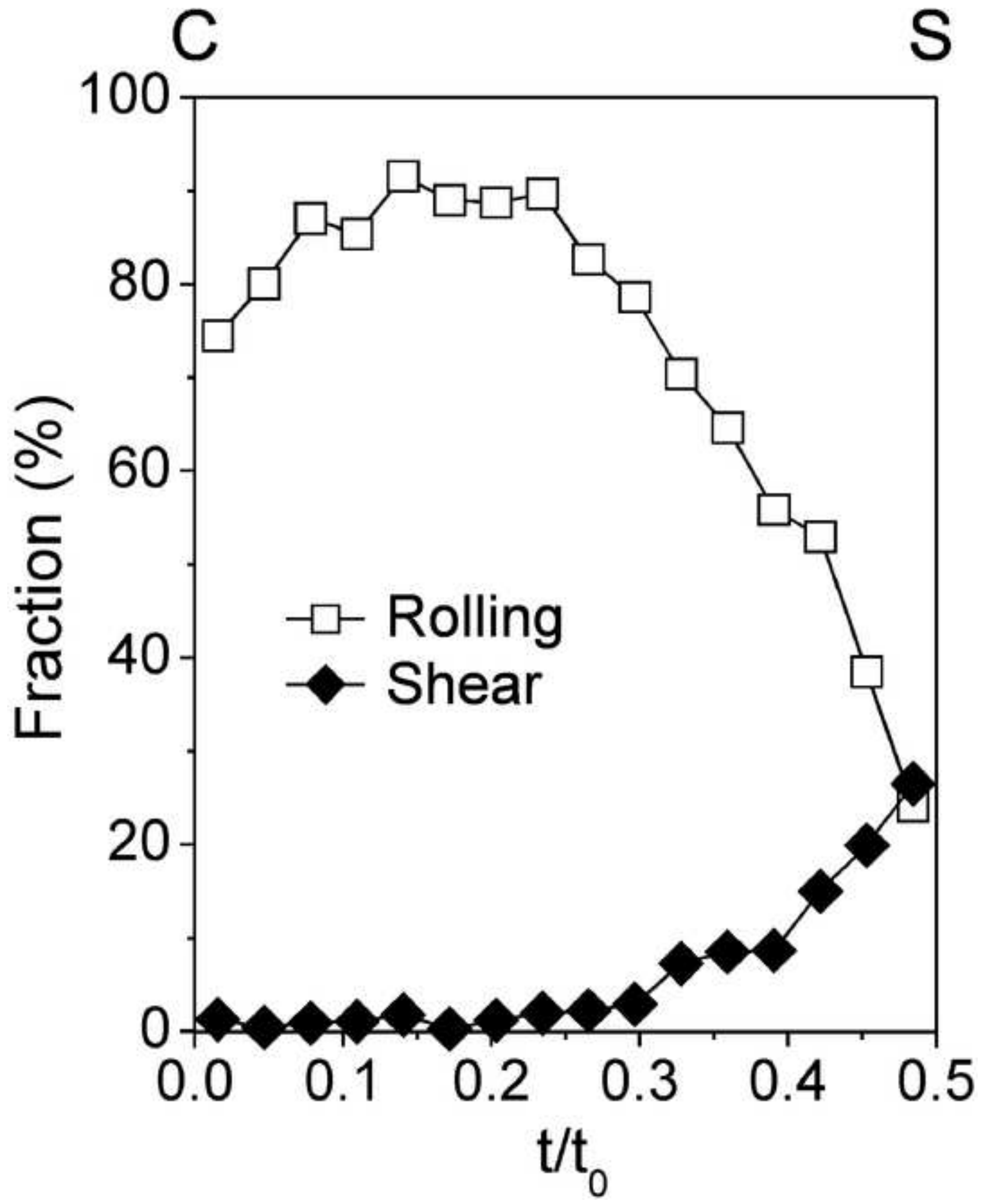




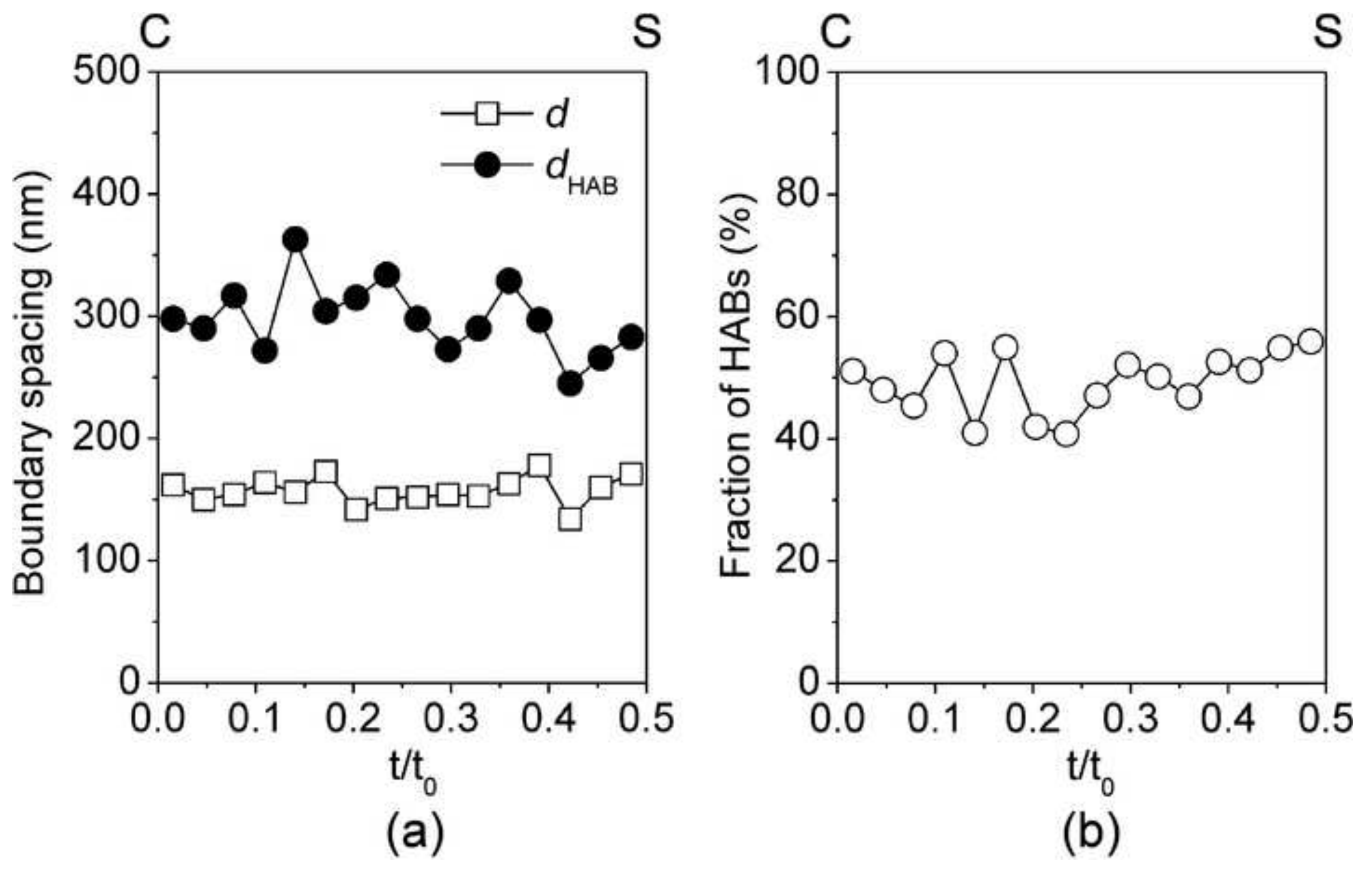




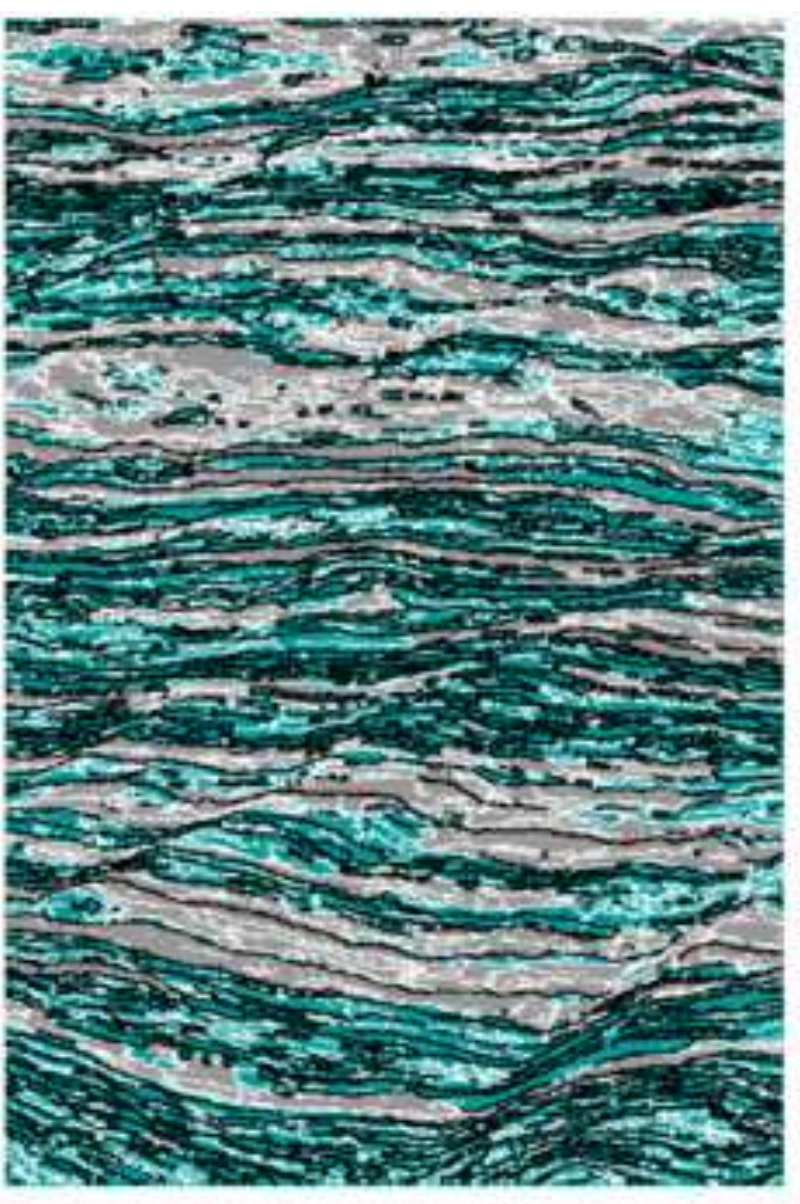

HMS

(a)

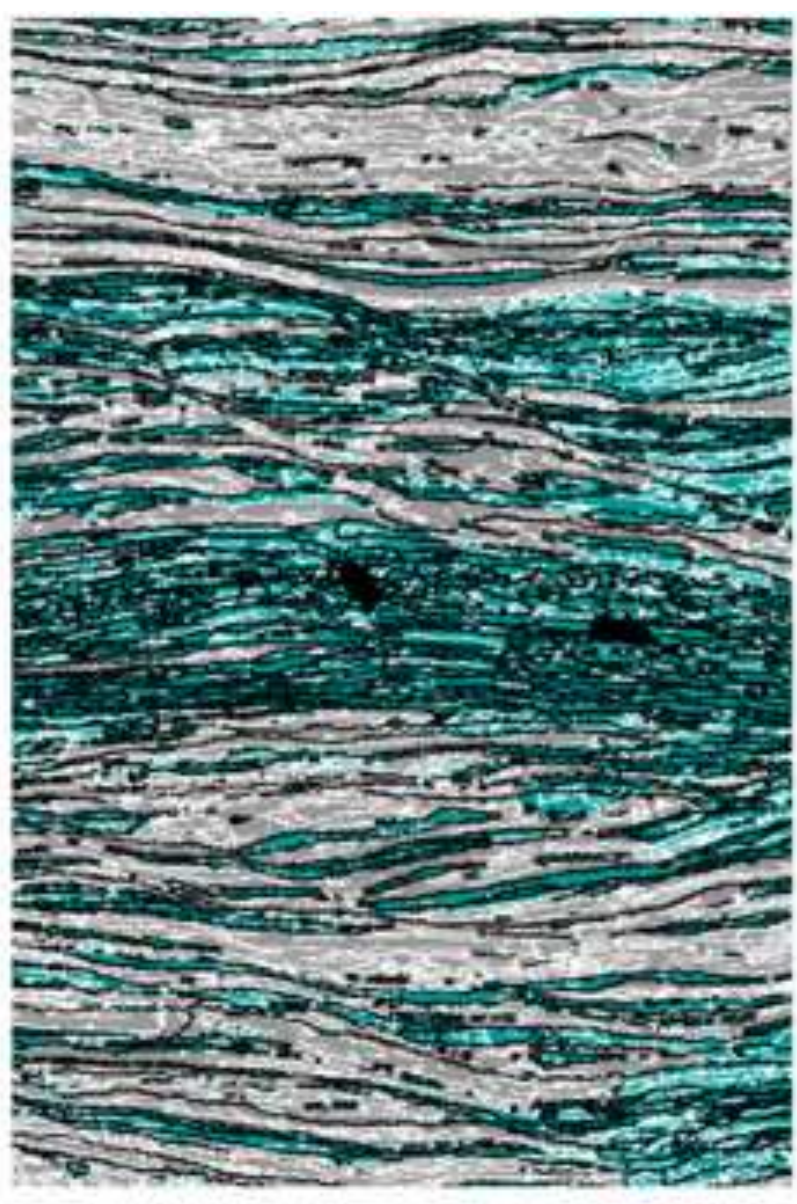

LMS

(b)

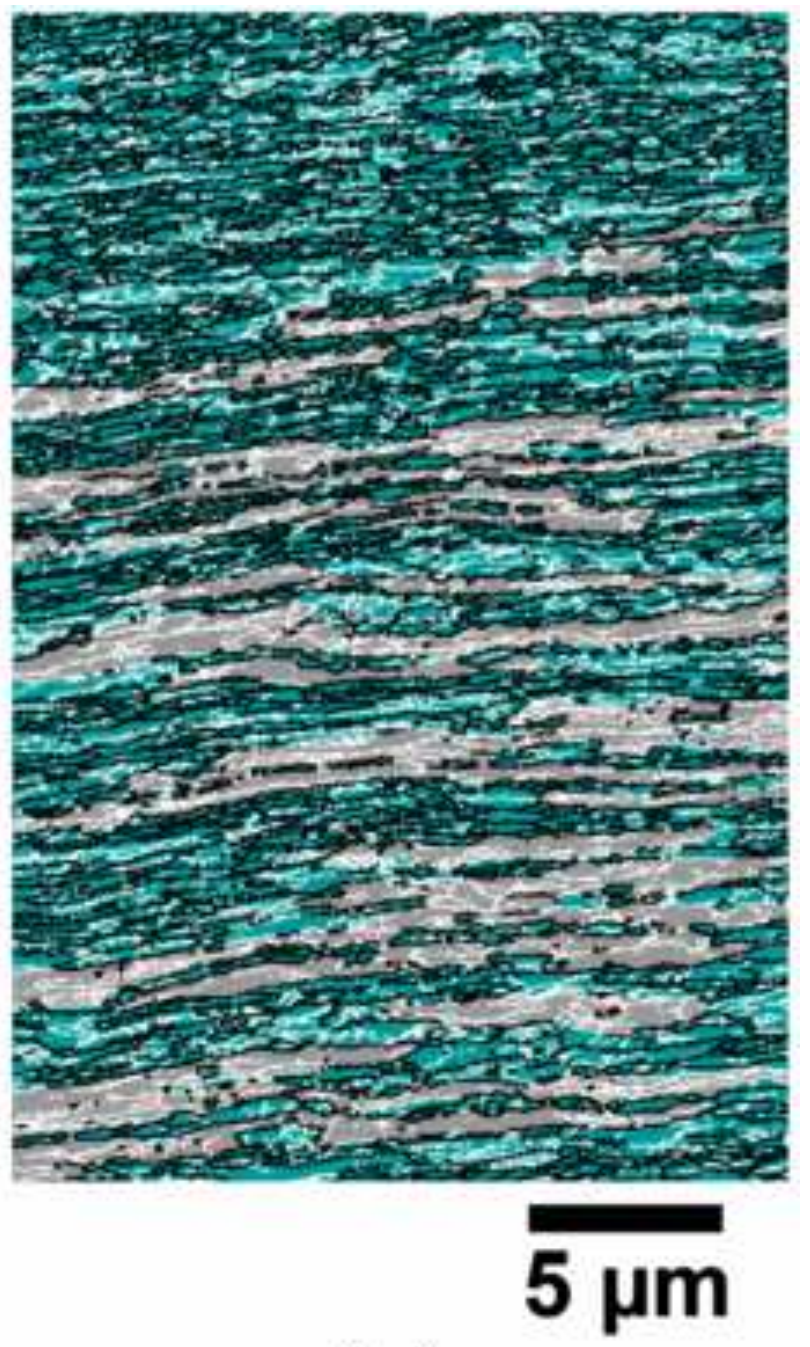

(c)

$5 \mu \mathrm{m}$ 


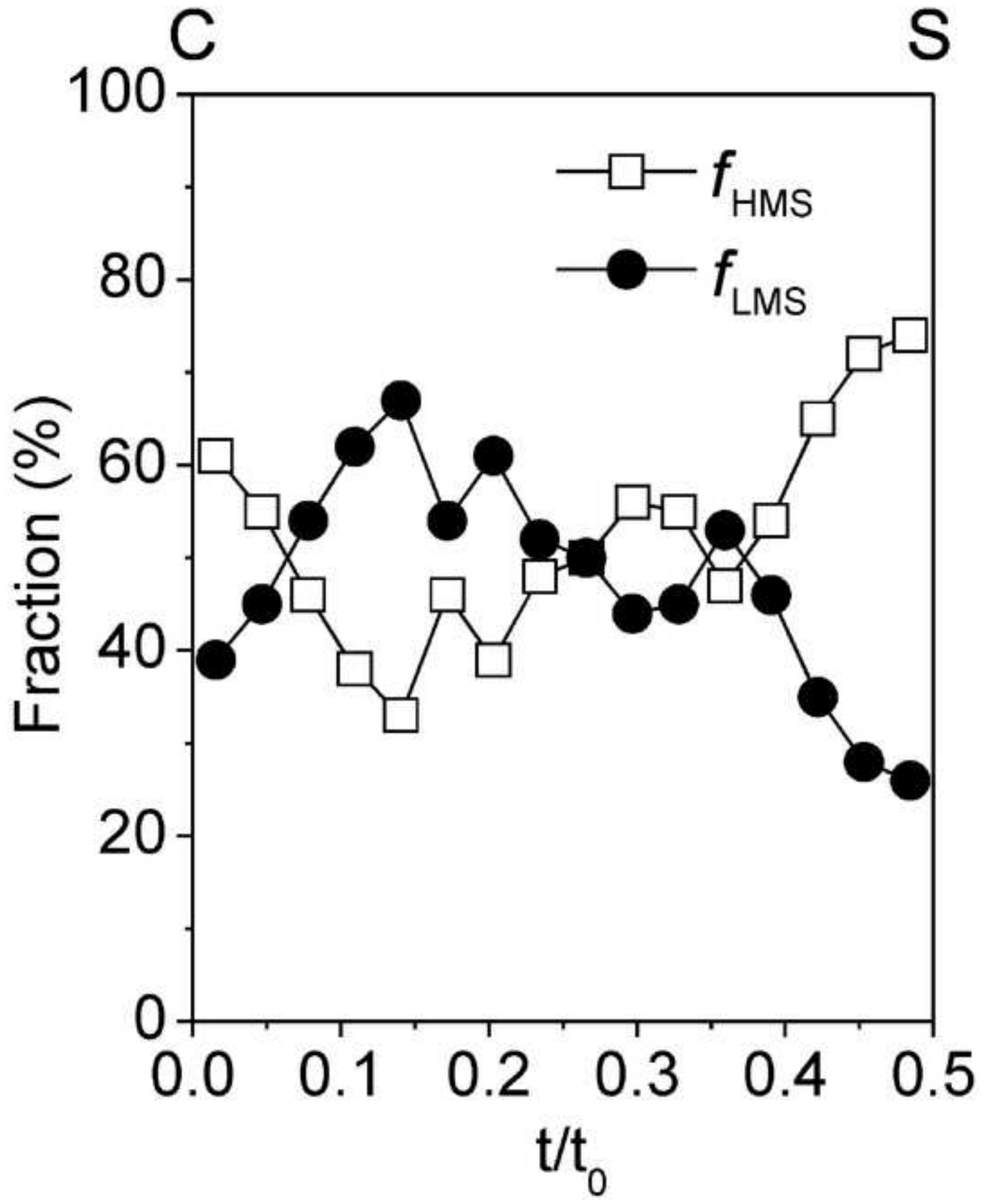




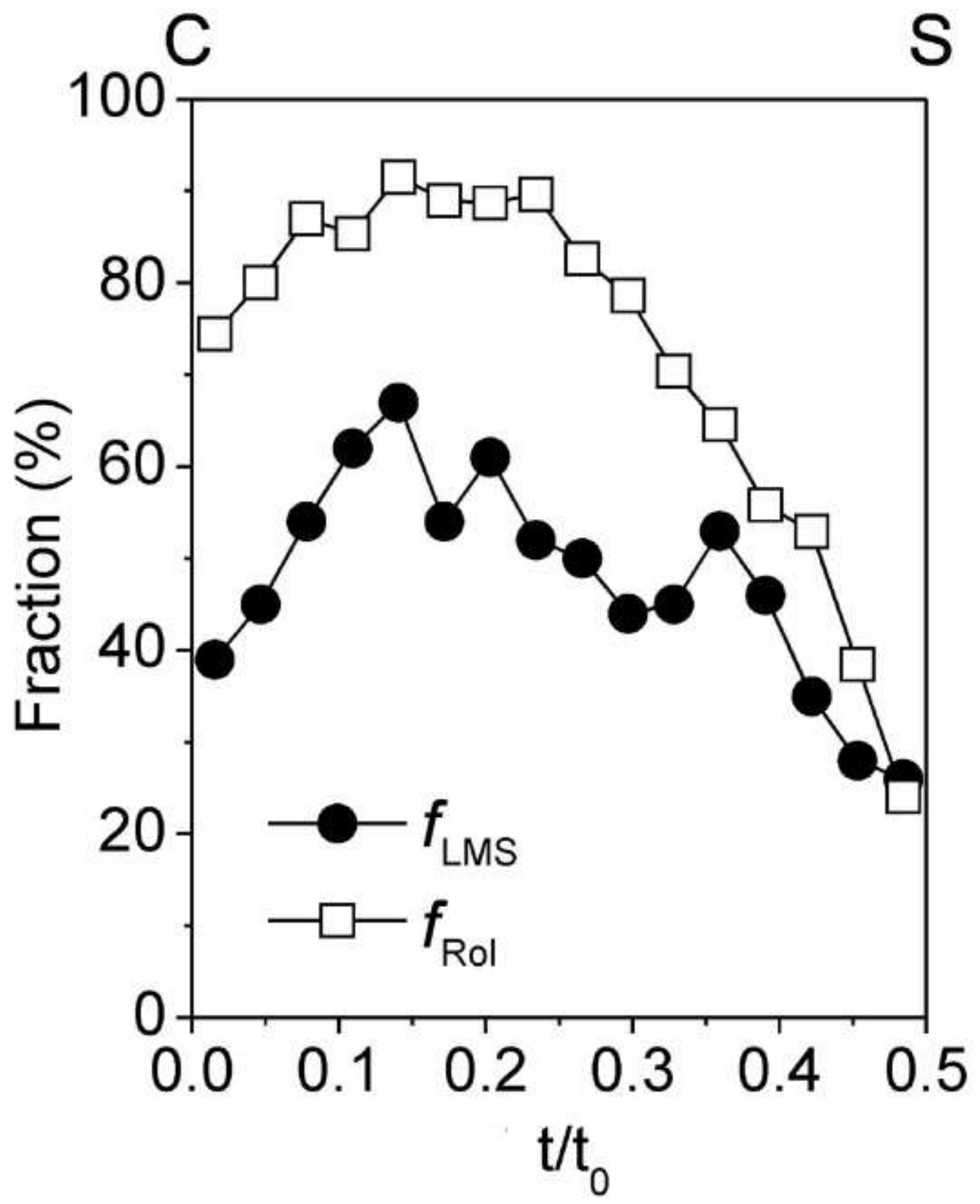


Table 1: Average values of $f_{\left[\theta>5^{\circ}\right]}, L_{\mathrm{A}\left[\theta>5^{\circ}\right]}$ and $f_{\mathrm{HMS}}$ in locations with significantly different fractions of the rolling texture components, $f_{\text {Rol }}$.

\begin{tabular}{lcccc}
\hline $\mathrm{t} / \mathrm{t}_{0}$ & $\bar{f}_{\left[\theta>5^{\circ}\right]}(\%)$ & $\bar{L}_{A\left[\theta>5^{\circ}\right]}\left(\mu \mathrm{m}^{-1}\right)$ & $\bar{f}_{\text {HMS }}(\%)$ & $\bar{f}_{\text {Rol }}(\%)$ \\
\hline $0-0.05$ & 75 & 6.8 & 58 & 77 \\
$0.1-0.25$ & 71 & 6.0 & 41 & 89 \\
$0.45-0.5$ & 80 & 7.2 & 73 & 31 \\
\hline
\end{tabular}

